\title{
Epidemiological Studies of Diabetes Mellitus in Denmark: 4. Clinical Characteristics of Insulin-Treated Diabetes
}

\author{
A. Green ${ }^{1}$ and P. Hougaard ${ }^{2}$ \\ ${ }^{1}$ University Institute of Clinical Genetics, Odense, and \\ ${ }^{2}$ Statistical Research Unit, The Danish Medical and Social Science Research Councils, Copenhagen, Denmark
}

\begin{abstract}
Summary. We report the clinical characteristics of all insulintreated diabetic patients ( 783 males and 716 females) living on July 11973 in a Danish county. In 18 patients diabetes was believed to be secondary to another disease or condition. Of all patients, $43 \%$ of the males and $55 \%$ of the females were $>$ age 50 years and $42 \%$ and $36 \%$ of males and females, respectively, had a disease duration of $<10$ years. The overall proportion of patients treated permanently with insulin from diagnosis was $85 \%$ and $79 \%$ in males and females, respectively, but within the subgroup of patients with current age $<30$ years these proportions were $99 \%$ and $96 \%$, respectively. Statistical analysis
\end{abstract}

indicated that insulin-treated diabetes is a clinically heterogeneous group of diseases; thus, low age at onset combined with immediate and permanent insulin treatment delineate one subtype, while relatively high age at onset and late start and/or interruption of insulin treatment delineate other subtype(s). It is estimated that the proportion of patients with truly Type 1 (insulin-dependent) diabetes is $>50 \%$ in this cross-sectional population of insulin-treated patients.

Key words: Epidemiology, insulin-treated diabetes, prevalence, heterogeneity.
In addition to elementary epidemiological data on diabetes (incidence, prevalence and mortality) information on the clinical characteristics of the current population of diabetics provides the necessary basis for planning diabetes care. Studies aiming at illustrating these aspects may furthermore give clues to the development of more appropriate classification criteria for diabetes which comprises a clinically and aetiologically heterogeneous group of diseases [1,2]. This report presents a description and analysis of the clinical characteristics of the prevalent (cross-sectional) population of all insulintreated diabetic patients, living on 1 July 1973 in a welldefined Danish region [3].

\section{Materials and Methods}

Funen County (approximately 450,000 inhabitants) constitutes a geographically well-defined and demographically representative sample of Denmark as a whole. By examining insulin prescriptions for a 5-month period, all insulin-treated diabetic patients (783 males and 716 females) living in Funen County on 1 July 1973 were identified [3]; in each case, diagnosis was confirmed and supplementary clinical data obtained from hospital and other medical records [3]. To evaluate ketosis-proneness all patients were checked against the computerized hospital register for Funen County with regard to admissions with ketosis or ketoacidosis included as discharge diagnosis within the period 1 July 1973-31 December 1981.
To evaluate clinical heterogeneity all patients were grouped according to sex and current age and each class was subdivided according to whether insulin treatment had been started $<1$ year after diagnosis and continued since then (group 1) or not (group 2). Only patients with known history of insulin treatment were included in this analysis, and to reduce selection bias because of underrepresentation in group 2 , only patients with diabetes diagnosed $<2$ years before 1 July 1973 were included. The difference of the average age at diagnosis (average group 2 - average group 1) was evaluated by a conventional t-test for each class separately. As a consequence of the crosssectional design of the study the two groups compared within each age and sex class have been selected due to the effect of mortality before the prevalence date; the mortality may depend on current age, sex and age at diagnosis, but in this analysis it is assumed to be independent of being in group 1 or group 2. Given this, the hypothesis tested specifies that the probability of being in group 1 compared to being in group 2 is independent of age at onset.

\section{Results}

Among the 783 males in the prevalent (cross-sectional) population of insulin-treated diabetic patient, nine had pancreatitis and three cancer of the pancreas before the diagnosis of diabetes, according to the medical records. Among the 716 females, five had pancreatitis and one cancer of the stomach with invasion into the pancreas before diabetes. These cases, all diagnosed after age 30 years, have been included in the following analyses. 
Table 1. The prevalent population of insulin-treated diabetic patients in Funen County, Denmark, 1 July 1973, distributed according to current age and duration of the disease

\begin{tabular}{|c|c|c|c|c|c|c|c|c|c|c|c|}
\hline \multirow{2}{*}{$\begin{array}{l}\text { Disease duration } \\
\text { (years) }\end{array}$} & \multirow{2}{*}{$\begin{array}{l}\text { Sex } \\
\text { male/female }\end{array}$} & \multicolumn{10}{|c|}{ Current age as of 1 July 1973 (years) } \\
\hline & & $0-9$ & $10-19$ & $20-29$ & $30-39$ & $40-49$ & $50-59$ & $60-69$ & $70-79$ & $80+$ & Total \\
\hline \multirow[t]{2}{*}{$0-9$} & M & 18 & 61 & 64 & 46 & 41 & 32 & 38 & 22 & 8 & 330 \\
\hline & $\mathrm{F}$ & 13 & 43 & 36 & 23 & 26 & 29 & 42 & 29 & 15 & 256 \\
\hline \multirow[t]{2}{*}{$10-19$} & M & & 10 & 47 & 43 & 48 & 44 & 46 & 21 & 3 & 262 \\
\hline & $\mathrm{F}$ & & 17 & 33 & 34 & 27 & 36 & 56 & 50 & 13 & 266 \\
\hline \multirow[t]{2}{*}{$20-29$} & M & & & 9 & 20 & 25 & 26 & 24 & 18 & 3 & 125 \\
\hline & $\mathrm{F}$ & & & 5 & 28 & 13 & 22 & 23 & 25 & 7 & 123 \\
\hline \multirow[t]{2}{*}{$30-39$} & M & & & & 4 & 7 & 14 & 10 & 6 & 0 & 41 \\
\hline & $\mathrm{F}$ & & & & 4 & 14 & 10 & 14 & 6 & 1 & 49 \\
\hline \multirow[t]{2}{*}{$40-49$} & M & & & & & 4 & 6 & 6 & 8 & 0 & 24 \\
\hline & $\mathrm{F}$ & & & & & 4 & 8 & 5 & 2 & 0 & 19 \\
\hline \multirow[t]{2}{*}{$50+$} & $\mathrm{M}$ & & & & & & 0 & 1 & 0 & 0 & 1 \\
\hline & $\mathrm{F}$ & & & & & & 1 & 2 & 0 & 0 & 3 \\
\hline \multirow[t]{2}{*}{ Total } & M & 18 & 71 & 120 & 113 & 125 & 122 & 125 & 75 & 14 & 783 \\
\hline & $\mathrm{F}$ & 13 & 60 & 74 & 89 & 84 & 106 & 142 & 112 & 36 & 716 \\
\hline Age-specific & M & 0.52 & 2.09 & 3.50 & 4.32 & 5.03 & 4.80 & 5.57 & 5.85 & 2.9 & 3.57 \\
\hline $\begin{array}{l}\text { prevalence rates } \\
\text { (per } 1,000)\end{array}$ & $\mathrm{F}$ & 0.40 & 1.87 & 2.30 & 3.46 & 3.31 & 4.06 & 5.96 & 7.05 & 5.6 & 3.25 \\
\hline
\end{tabular}

Table 2. The prevalent population of insulin-treated diabetic patients in Funen County, Denmark, 1 July 1973, distributed according to history of insulin-treatment and current age

\begin{tabular}{|c|c|c|c|c|c|c|}
\hline \multirow[t]{2}{*}{$\begin{array}{l}\text { Current age as of } \\
1 \text { July } 1973 \text { (years) }\end{array}$} & \multicolumn{2}{|c|}{$\begin{array}{l}\text { Insulin from diagnosis and } \\
\text { continued }^{\mathrm{a}}\end{array}$} & \multicolumn{2}{|c|}{$\begin{array}{l}\text { No insulin from diagnosis and/or } \\
\text { discontinuation of insulin }\end{array}$} & \multicolumn{2}{|c|}{$\begin{array}{l}\text { Unknown history of } \\
\text { treatment }\end{array}$} \\
\hline & Male & Female & Male & Female & Male & Female \\
\hline $20-29$ & $113(10)$ & $70 \quad(9)$ & $2(0)$ & $4(1)$ & $5 \quad(0)$ & $\begin{array}{ll}0 & (0)\end{array}$ \\
\hline $30-39$ & $93 \quad(9)$ & $82 \quad(7)$ & $4(0)$ & $5(1)$ & $16 \quad(2)$ & $2 \quad(0)$ \\
\hline $40-49$ & $105(10)$ & $67 \quad(6)$ & $9(0)$ & $6(1)$ & $11 \quad(0)$ & 11 (2) \\
\hline $70-79$ & $19 \quad(3)$ & $55 \quad(9)$ & 27 (1) & $36(2)$ & $29 \quad(2)$ & 21 \\
\hline $80+$ & $3 \quad(0)$ & 13 (1) & 9 (1) & $16(0)$ & $2 \quad(0)$ & $7 \quad(0)$ \\
\hline Total & 558 & $500(60)$ & $101(5)$ & $131(7)$ & 124 (11) & $85(13)$ \\
\hline
\end{tabular}

Number of patients admitted to a hospital within the following $81 \frac{1}{2}$ years with ketosis as a discharge diagnosis is given in parentheses.

${ }^{a}$ Insulin treatment started at latest 1 year after diagnosis and continued since then;

${ }^{\mathrm{b}}$ insulin treatment started later than 1 year after diagnosis and/or discontinued for period(s) of more than 1 week

Table 1 shows for each sex the distribution of the patients according to current age (at the prevalence date) and the corresponding duration of disease. For males, $42.9 \%$ and for females $55.3 \%$ were $>50$ years of age. Only $8.4 \%$ of the males, and $9.9 \%$ of the females had a duration of diabetes of $\geqslant 30$ years, whereas $42.1 \%$ (males) and 35.8\% (females) had diabetes diagnosed $<10$ years before the prevalence date.

The history of insulin treatment is shown in Table 2. In virtually all patients under the age of 30 years, insulin was given permanently $<1$ year after diagnosis (group 1). With increasing current age, the proportion of individuals not treated with insulin from diagnosis and/or with interruption in insulin treatment (group 2) increased; overall this proportion was $15.3 \%$ and $20.8 \%$ for males and females respectively, excluding patients with unknown history.
Among group 1 patients $53(9.5 \%)$ males and 60 $(12.0 \%)$ females were admitted at least once during the following $8 \frac{1}{2}$ years with ketosis or ketoacidosis as discharge diagnosis; the corresponding results for group 2 patients were five $(5.0 \%)$ males and seven $(5.3 \%)$ females; for the two sexes combined this difference is significant $\left(\mathrm{X}_{1}^{2}=6.62 ; 0.01<p<0.0 .25\right)$.

An overview of the anti-diabetic treatment with reference to the prevalence date is given in Table 3 . For 12 males and six females it was known that they were treated with insulin, but information of the exact daily dosage could not be obtained. Among males 39 patients $(5.0 \%)$ and among females 53 patients $(7.4 \%)$ were given oral hypoglycaemic drugs in combination with insulin; the proportion was considerably smaller in age groups $<30$ years. The overall average daily dose was 41.2 and $36.8 \mathrm{IU} /$ day for males and females, respective- 
Table 3. Anti-diabetic treatment in the prevalence population of insulin-treated diabetic patients in Funen County, Denmark from 1 July 1973

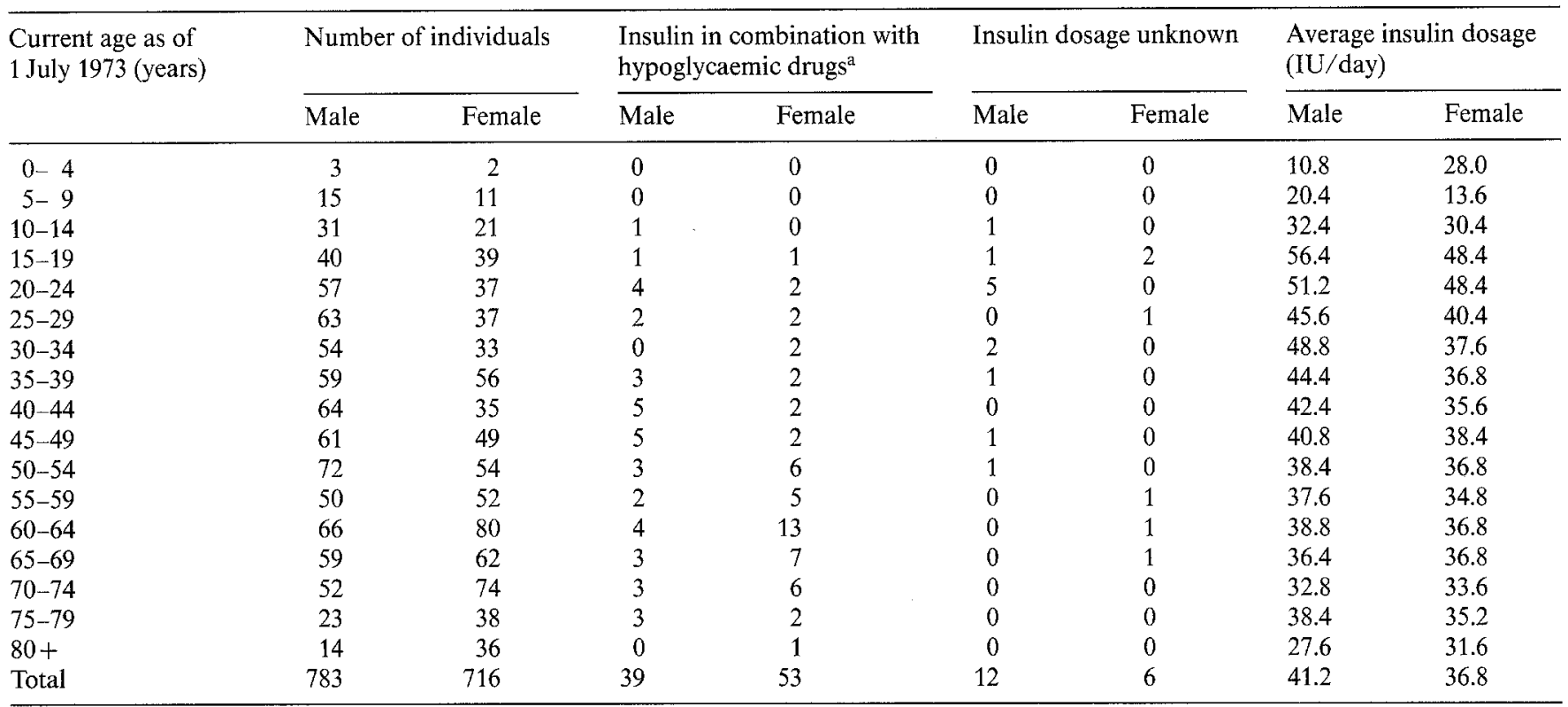

a Not included in the calculation of average insulin dosage (last column)

Table 4. Statistical analysis of clinical heterogeneity in the prevalent population of insulin-treated diabetic patients in the Funen County, Denmark from 1 July 1973

\begin{tabular}{|c|c|c|c|c|c|c|}
\hline \multirow{2}{*}{$\begin{array}{l}\text { Current age as } \\
\text { of } 1 \text { July } \\
1973 \text { (years) }\end{array}$} & \multicolumn{2}{|c|}{ Included in analysis } & \multirow{2}{*}{$\begin{array}{l}\text { Difference of } \\
\text { average age at } \\
\text { diagnosis }\end{array}$} & \multirow{2}{*}{$\begin{array}{l}\text { Degrees of } \\
\text { freedom }\end{array}$} & \multirow[t]{2}{*}{ t-value } & \multirow{2}{*}{$\begin{array}{l}\mathrm{p} \text {-value } \\
\text { (two-sided) }\end{array}$} \\
\hline & Group $1^{a}$ & Group $2^{b}$ & & & & \\
\hline \multicolumn{7}{|l|}{ Males } \\
\hline $0-19$ & 79 & 0 & - & - & - & - \\
\hline $20-29$ & 105 & 2 & 3.65 & 105 & 0.83 & 0.41 \\
\hline $50-59$ & 79 & 15 & 9.09 & 92 & 2.97 & 0.004 \\
\hline $60-69$ & 49 & 35 & 7.95 & 82 & 3.12 & 0.002 \\
\hline $70+$ & 19 & 35 & 4.70 & 52 & 1.13 & 0.26 \\
\hline \multicolumn{7}{|l|}{ Females } \\
\hline $0-19$ & 61 & 1 & 4.75 & 60 & 1.15 & 0.25 \\
\hline $20-29$ & 65 & 4 & 7.45 & 67 & 2.68 & 0.01 \\
\hline $70+$ & 62 & 52 & 1.69 & 112 & 0.87 & 0.39 \\
\hline
\end{tabular}

a Group 1: Insulin treatment started at latest 1 year after diagnosis, continued since then and diagnosis established before 1 July 1971 ;

${ }^{\mathrm{b}}$ group 2: Insulin treatment started later than 1 year after diagnosis and/or discontinued for period(s) of more than 1 week and diagnosis established before 1 July 1971

$1 y$; small average values were found in the three youngest and the oldest age classes, and high values were in particular found in the age class 15-24 years.

The statistical analysis of the combined information of age at diagnosis and history of insulin treatment is shown in Table 4 . In all but one with a marginal difference only, the average age at onset was higher among group 2 patients compared to group 1 patients, and the difference was significant in six out of 13 classes; under the null hypothesis this was expected to occur in only one class by chance.

\section{Discussion}

The patients in the present study were identified with an estimated degree of ascertainment of about $98 \%$ from a well-defined total population [3] and, therefore, we believe the results give a reliable and generally valid picture of the clinical features of the current cross-sectional population of insulin-treated diabetic subjects. Thus, this population is characterized by patients in whom diabetes, except for a very few cases, is of primary (idiopathic) type; furthermore, the patients have on average 
had their disease for a relatively short period of time (Table 1) and this supports our previous finding that among insulin-treated diabetic patients of current age $\geqslant 60$ years only a few per cent have had the diagnosis established before age 30 years [3]. The relatively short average disease duration may most likely be explained by the excess mortality among diabetics.

Only a small proportion of the patients were treated with insulin in combination with oral hypoglycaemic drugs (Table 3 ); this proportion is probably smaller today because phenformin was withdrawn after the prevalence date of our study.

From an epidemiological point of view classification of diabetic patients according to whether or not they are on insulin treatment is very convenient, but this simple criterion does not conform with the newly established clinical criteria $[1,2]$. Thus, the group of insulintreated diabetics comprises truly Type 1 (insulin-dependent) diabetics as well as an unknown proportion of patients with other diabetes types. Our results support heterogeneity, and we tentatively conclude that low age at diagnosis combined with immediate and permanent insulin treatment seems to delineate one type (probably Type 1 diabetes), while relatively high age and late start and/or interruption of insulin treatment delineate one or more other type(s). This conclusion is also supported by the significant higher proportion of group 1 diabetics with subsequent documented episodes of ketosis as compared to group 2 , but unfortunately the absolute numbers are too small to permit an estimation of the true number of Type 1 diabetics in the prevalent population of insulin-treated diabetics. Recently, a detailed clinical follow-up examination of 577 patients from the present material, characterized by having diabetes diagnosed before age 30 years, revealed that in all patients, except one, virtually no endogeneous insulin pro- duction was left as assessed by C-peptide level (Sjølie, personal documentation). This, combined with the epidemiological observation that patients with diagnosis before age 30 years comprise approximately $50 \%$ of the prevalent population of insulin-treated diabetics [3], indicates that at least half of the current group of insulintreated diabetics have Type 1 diabetes.

Longitudinal studies of newly diagnosed patients in whom the course of disease is monitored according to a standard protocol would provide the basis for more valid classification criteria as well as an evaluation of the proportion of patients who initially do not require insulin, but later become truly insulin-dependent. Thus, such studies are highly needed and recommended.

Acknowledgements. Financial support was obtained from the Danish Medical Research Council (grant no.12-1035) to AG.

\section{References}

1. National Diabetes Data Group (1979) Classification and diagnosis of diabetes mellitus and other categories of glucose intolerance. Diabetes 28: 1039-1057

2. WHO Expert Committee on Diabetes Mellitus (1980) Second Report. WHO, Geneva: Technical Report Series 646

3. Green A, Hauge M, Holm NV, Rasch LL (1981) Epidemiological studies of diabetes mellitus in Denmark. II. A prevalence study based on insulin prescriptions. Diabetologia 20: 468-470

Received: 27 September 1982

and in revised form: 27 June 1983

Dr. A. Green

University Institute of Clinical Genetics

J. B. Winsløwsvej 17

DK-5000 Odense C

Denmark 